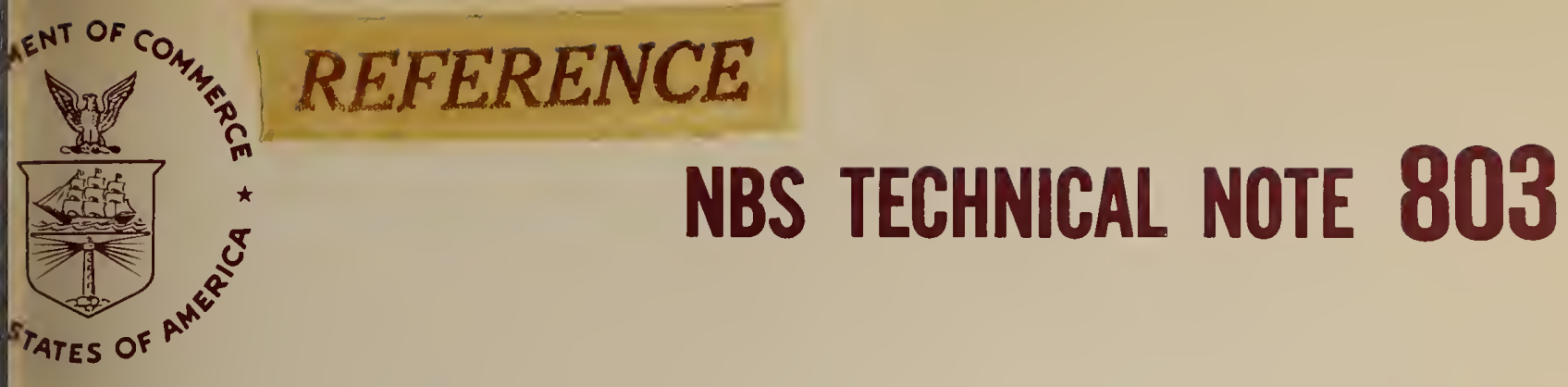

\title{
A Guide to \\ Networking Terminology
}

$Q G$

100

5753

.803

1974

U.S. PARTMENT OF OMMERCE National Bureau of

Standards 
The National Bureau of Standards ' ${ }^{1}$ was established by an act of Congress March 3, 1901. The Bureau's overall goal is to strengthen and advance the Nation's science and technology and facilitate their effective application for public benefit. To this end, the Bureau conducts research and provides: (1) a basis for the Nation's physical measurement system, (2) scientific and technological services for industry and government, (3) a technical basis for equity in trade, and (4) technical services to promote public safety. The Bureau consists of the Institute for Basic Standards, the Institute for Materials Research, the Institute for Applied Technology, the Institute for Computer Sciences and Technology, and the Office for Information Programs.

THE INSTITUTE FOR BASIC STANDARDS provides the central basis within the United States of a complete and consistent system of physical measurement; coordinates that system with measurement systems of other nations; and furnishes essential services leading to accurate and uniform physical measurements throughout the Nation's scientific community, industry, and commerce. The Institute consists of a Center for Radiation Research, an Office of Measurement Services and the following divisions:

Applied Mathematics - Electricity - Mechanics - Heat - Optical Physics - Nuclear Sciences $^{2}$ - Applied Radiation " - Quantum Electronics ${ }^{3}$ - Electromagnetics ${ }^{3}$ — Time and Frequency " - Laboratory Astrophysics" - Cryogenics".

THE INSTITUTE FOR MATERIALS RESEARCH conducts materials research leading to improved methods of measurement, standards, and data on the properties of well-characterized materials needed by industry, commerce, educational institutions, and Government; provides advisory and research services to other Government agencies; and develops, produces, and distributes standard reference materials. The Institute consists of the Office of Standard Reference Materials and the following divisions:

Analytical Chemistry - Polymers - Metallurgy — Inorganic Materials — Reactor Radiation - Physical Chemistry.

THE INSTITUTE FOR APPLIED TECHNOLOGY provides technical services to promote the use of available technology and to facilitate technological innovation in industry and Government; cooperates with public and private organizations leading to the development of technological standards (including mandatory safety standards), codes and methods of test; and provides technical advice and services to Government agencies upon request. The Institute consists of a Center for Building Technology and the following divisions and offices:

Engineering and Product Standards - Weights and Measures - Invention and Innovation - Product Evaluation Technology - Electronic Technology — Technical Analysis - Measurement Engineering - Structures, Materials, and Life Safety ${ }^{4}$ — Building Environment ${ }^{4}$ - Technical Evaluation and Application ${ }^{4}$ — Fire Technology.

THE INSTITUTE FOR COMPUTER SCIENCES AND TECHNOLOGY conducts research and provides technical services designed to aid Government agencies in improving cost effectiveness in the conduct of their programs through the selection, acquisition, and effective utilization of automatic data processing equipment; and serves as the principal focus within the executive branch for the development of Federal standards for automatic data processing equipment, techniques, and computer languages. The lnstitute consists of the following divisions:

Computer Services - Systems and Software - Computer Systems Engineering - Information Technology.

THE OFFICE FOR INFORMATION PROGRAMS promotes optimum dissemination and accessibility of scientific information generated within NBS and other agencies of the Federal Government; promotes the development of the National Standard Reference Data System and a system of information analysis centers dealing with the broader aspects of the National Measurement System; provides appropriate services to ensure that the NBS staff has optimum accessibility to the scientific information of the world. The Office consists of the following organizational units:

Office of Standard Reference Data - Office of Information Activities - Office of Technical Publications - Library - Office of International Relations.

1 Headquarters and Laboratories at Gaithersburg, Maryland, unless otherwise noted; mailing address Washington, D.C. 20234.

2 Part of the Center for Radiation Research.

3 Located at Boulder, Colorado 80302.

- Part of the Center for Building Technology. 


\section{A Guide to Networking Terminology}

A. J. Neumann

Systems and Software Division

Institute for Computer Sciences and Technology

National Bureau of Standards

Washington, D.C. 20234

Sponsored by

The National Science Foundation

18 th and $G$ Street, N.W.

Washington, D.C. 20550

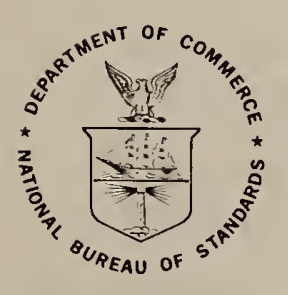

U.S. DEPARTMENT OF COMMERCE, Frederick B. Dent, Secretary

NATIONAL BUREAU OF STANDARDS, Richard W. Roberts, Director

Issued March 1974 
National Bureau of Standards Technical Note 803

Nat. Bur. Stand. (U.S.), Tech. Note 803, 29 pages (Mar. 1974)

CODEN: NBTNAE 
This report is one of a series of publications produced by the Institute for Computer Sciences and Technology, National Bureau of Standards, under Grant AG-350 from the National Science Foundation.

This grant supports a broad program of investigation into the foundations of computer networking in support of scientific and related educational efforts.

A listing of completed and planned publications produced by the Institute under this grant follows:

1. Primary Issues in User Needs

D. W. Fife

Chapter 10 in Networks for Research and Education:

Sharing of Computer and Information Resources Nationwide MIT Press, Cambridge, Mass.

Expected Publication Spring 1974

2. Some Technical Considerations for Improved Service to Computer Users

T. N. Pyke, Jr.

COMPCON, 1973

Seventh Annual IEEE Computer Society International conference

3. Computer Networking Technology - A State-of-the-Art Review R. P. Blanc and T. N. Pyke, Jr. COMPUTER Magazine Computer society of the IEEE August 1973

4. Review of Network Management Problems and Issues A. J. Neumann

NBS Technical Note 795 October 1973

5. Annotated Bibliography of the Literature on Resource Sharing Computer Networks

R. P. Blanc, I. W. Cotton, T. N. Pyke, Jr., and S. W. Watkins NBS Special Publication 384

September 1973

6. Network Management Survey

I. W. Cotton

NBS Technical Note 805

Expected Publication January 1974 
7. User Procedures Standardization for Network Access A. J. Neumann

NBS Technical Note 799

october 1973

8. Review of Computer Networking Technology

R. P. Blanc

NBS Technical Note 804

February 1974

9. Microeconomics and the Market for Computer Services I. W. Cotton

Submitted for Publication

10. Cost Analyses for Computer Communications

R. P. Blanc

NBS Technical Note

Expected Publication Spring 1974

11. Network User Information Support

A. J. Neumann

NBS Technical Note 802

December 1973

12. Quality Service Assurance Experiments

R. Stillman

NBS Technical Note 800

January 1974

13. A Guide to Networking Terminology

A. J. Neumann

NBS Technical Note 803

February 1974

14. Research Considerations in Computer Networking

D. W. Fife

NBS Technical Note 801

Expected Publication Spring 1974 
The basis for this report was a "Preparatory Glossary of Networking Terminology for the National Science Computer Network," which was originally prepared by $R$. N. Freemire of NBS during the fall of 1972.. Subsequently, the scope of the content was broadened, format and reference structure were changed, new terms and definitions were added, some definitions were deleted, and some were rewritten. This effort was materially aided by an ad hoc working group consisting of R. Blanc, G. Clark, and B. Lucas, all of the Institute for Computer Sciences and Technology, who reviewed several drafts and collaborated in selection of terms to be defined. In addition, I. W. Cotton, D. W. Fife and P. Meissner, all of the ICST, made valuable suggestions. The many contributions of all of the above are gratefully acknowledged. 


\section{Page}

1. INTRODUCTION . . . . . . . . . . . . I 1

1.1 scope . . . . . . . . . . . . 2

1.2 Glossary Conventions . . . . . . . . 4

2. GLOSSARY . . . . . . . . . . . . 5

3. LIST OF SOURCE MATERIAL . . . . . . . . 19 
A. J. Neumann

A selected set of terms and definitions relating to computer networking is presented in a coherent manner. An introduction gives the rationale for the glossary, defines the scope by a brief tutorial overview, and states the glossary format and conventions. The glossary is arranged alphabetically and contains about 140 definitions and associated terms. The sources of many terms are cited and modifiers indicate the status of definitions. A complete listing of source material is appended.

Key Words: Computer networks; glossary; telecommunications; teleprocessing; terminology; vocabulary.

\section{INTRODUCTION}

The purpose of this guide is to assist in technical communications. This task is becoming increasingly difficult as computer networking efforts are expanding from pure research within a closely knit community towards both development of commercial networks and diversity of applications at user and server nodes.

Technical language serves as a communications medium. It is based on technological concepts and documented terms and on definitions which communicate these concepts. In the computer networking field, the problems of terminology are compounded by the merger of two distinct technological communities, namely that of data processing and computers, and that of telecommunications.

While the digital computer field now covers a time span of about 25 years, telecommunications is at least three times older. The two fields have existed side by side for some time, and terminology has developed independently in both fields, often dealing with similar concepts. Now, with emerging computer networks, communications technology is becoming part of teleprocessing, and the telecommunications industry is embracing computers and data processing methods. As a result, the two fields are merging rapidly. With technology progressing, many old concepts remain, though often with new names, while new concepts arise, assuming old names. In due course, problems of language and terminology arise. It therefore seems desirable, if not imperative, to develop a common terminology that covers all facets of networking. The objective of this guide is to bridge both the time gap between the communications and computer disciplines and the inter-disciplinary gap.

This paper may conceivably be of use to a variety of users. The casual technical reader may find explanations for terms with which he 
has not been familiar in the past. The more sophisticated reader may come upon multiple definitions and may be guided toward a sharper formulation of concepts in developing or writing out his thoughts. Those concerned with the creation of new concepts may find existing terms which could subsume their ideas. Finally, the creators of new terms coming across related terms or concepts may decide against a new term, since present terminology appears to be adequate.

With networking developments being in a state of flux, the creation of a new term might lead to confusion and impede communications in cases where adequate old terms exist. Here, the consolidation of common concepts and simplification of the technical language would be a more useful endeavor.

Readers of this guide are encouraged to communicate with the author and point out inconsistencies, errors, or omissions. Some of the material in this report may be introduced into proposed draft standards or other technical documentation, if it is not already contained in official sources. Reader feedback on both errörs of omission and errors of commission would, therefore, be highly appreciated.

This guide consists of three parts: the Introduction develops the rationale for this report. It also indicates the scope of the glossary by listing some of the terms, and explains the layout, conventions, and references of the appended glossary. Section 2 is a networking glossary which has been kept small on purpose. Even so, it does contain a selected representative sample of networking terms and definitions, in addition to references to other terms or concepts in the glossary and to the source material. Section 3 is a selected list of source material and general references. It is comprised of glossaries, vocabularies, standards documents, literature references, and sources of commercial documentation.

\subsection{Scope}

The scope of the glossary focuses on general concepts such as topology, nodes and links, hardware, software, operations and processes, messages and message structures as well as measures of network properties.

Source references lead to more detailed definitions and to additional related concepts. The brief survey also illustrates the difficulties facing glossary developers and users. Among them are synonymy, homonomy, change of meaning in different context and over time, and differences in generality.

COMPUTER NETWORKS ${ }^{1}$ CONSISt of LINKS and NODES. The concepts of general NETWORKS, and computer networks overlap, e.g., a science

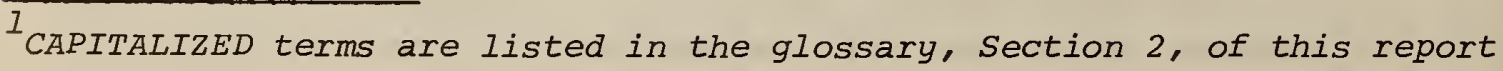


information network consisting of manual information center nodes that are linked by the mails, the public telephone network, and direct human conversation may be transformed into a science COMPUTER NETWORK. By so doing, the nodes become DATA TERMINAL INSTALLATIONS involving computers, TERMINALS, and DISPLAYS. The links may become automated DATA LINKS that permit automatic communication between data SOURCES and data SINKS. NODES contain HARDWARE, SOFTWARE, and people. Network operations are made possible by human procedures and inter-computer PROTOCOLS.

The NETWORK TOPOLOGY is related to network design, operations, reliability, and operating cost. A FULLY CONNECTED DISTRIBUTED NETWORK has more links for the same number of nodes than either a PARTIALLY CONNECTED NETWORK or a simple STAR NETWORK. Differing forms of network control are reflected in CENTRALIZED or DECENTRALIZED NETWORKS, in HIERARCHICAL NETWORKS, as WEII as in MULTIPOINT Or POINT-TO-POINT connections of TERMINALS.

The term network NODE may have a variety of connotations. In the most abstract sense, a network mathematician may be concerned with pure network topology. For this reason, he may want to minimize the number of NODES (1) ${ }^{2}$, LINKS (I) or he may optimize a network configuration. The hardware engineer, on the other hand, is concerned with NODES (2) in terms of equipment configurations, specifications for DATA TERMINAL EQUIPMENT, DATA COMMUNICATION EQUIPMENT and TERMINAL INSTALLATIONS. Others, such as network users, are concerned with SERVICE NODES or HOST COMPUTER NODES. A variety of HARDWARE and SOFTWARE may be installed at network nodes depending on their major function. Programmable digital computers, in this context may act in a variety of ways: as SWITCHING COMPUTERS, FRONT END COMPUTERS, or CONCENTRATORS.

LINK is a general term, and its specific meaning is either determined by the context in which it will be used or it must be explicitly stated. A librarian's service function acts as a LINK (I) in a generalized network model of human NODES (I) and document repository NODES (1). Since a variety of electronic communications LINKS (2) are utilized in computer networks, the impact of TELECOMMUNICATIONS terminology mist be taken into account. Terms from many sources such as telegraphy, telephone, radio, and satellite communications are commonly used. Distinctions of meaning exist between the terms LINE, CHANNEL, CIRCUIT, and VIRTUAL CIRCUIT. Sometimes they may be used synonymously, in other cases, more detailed concepts require more specific terms. There are INTERFACES (1) between hardware components, equipments providing INTERFACES (2), and software INTERFACES (3).

While a computer network might be viewed as a static assembly of TERMINAL INSTALLATIONS, DATA COMMUNICATION EQUIPMENT and CIRCUITS, it becomes operational through running programs and dynamic interaction of

Numbers in parentheses refer to the definition numbers listed under the
preceding CAPITALIZED term in the glossary. 
HARDWARE and SOFTWARE. LOGON, LOGOFF, and ACCESS CONTROL procedures are part of the user aCCESS PROTOCOL. CONVERSATIONAL operation or BATCH PROCESSING are used depending on user needs. MODEM-to-modem protocols, POLLING and SELECTING protocols for MULTIPOINT CONNECTIONS as well as computer-to-computer protocols provide the DATA LINKS necessary for network operations.

Messages may be transmitted by CIRCUIT SWITCHING or MESSAGE SWITCHING. PACKET SWITCHING may be considered a special form of STORE AND FORWARD message switching.

Well thought-out definitions are required to delineate the legal and jurisdictional boundaries of networks. In addition, the interface between customer-owned and COMMUNICATIONS COMMON CARRIER equipment is a crucial part of operations and network maintenance. REGULATORY AGENCIES become involved in setting TARIFFS to be charged by COMMON and SPECIALIZED COMMUNICATIONS CARRIERS. These charges affect system cost and user operating costs alike.

Messages, entered or received by a network user, are processed by TERMINALS, DATA COMMUNICATIONS EQUIPMENT, SWITCHING COMPUTERS, OI HOST COMPUTERS. Formats involve FRAMES, BLOCKS, PACKETS, HEADERS, and TEXT.

Certain system measures, such as BAUD, BIT TRANSFER RATE, CONNECT TIME, CPU TIME, and RESPONSE TIME, provide capabilities for accounting, performance measurement, and quality control.

This brief overview indicates the scope of the glossary and illustrates the variability of terms depending on the context within which they are used, other multiple meanings in usage, and the fundamental difficulty of naming and defining general and specific concepts. The following section outlines the conventions observed in the glossary part of this report.

\subsection{Giossary Conventions}

The terms in this glossary are listed alphabetically. Multiple terms are listed in their spoken, natural order. Multiple definitions of the same term are identified by serial numbers in parentheses. This occurs for two major reasons: in cases where there are distinct, different meanings (homonomy), e.g., DATA SET (1), (2) or in cases where different sources are identified with slightly different, but well established definitions, e.g., TERMINAL INSTALLATION (1) and (2). Parentheses in compound terms indicate words which are often omitted if the context permits it.

The following cross-references are used: synonymy is indicated by the symbol " "Syn:", e.g. MODEM ... Syn: DATA SET. The definition is listed only under one term, and the "see" reference refers to that particular term. Related concepts are indicated by "see also:," e.g., NETWORK REDUNDANCY . . . see also: LINK REDUNDANCY LEVEL. Opposite or contrasting concepts are indicated by a "Compare" reference. 
Source codes are used liberally. They may be appended either to the term being defined or to its definition(s). The source code refers generally to a family of source documents, listed in section 3, which may range from first drafts, through documents officially proposed at standardization meetings, to nationally or internationally accepted standards or recommendations. Citing the exact first sources would require much historical research and, therefore, be prohibitively time consuming. For this reason, only a general source code is listed.

Source code qualifiers indicate modifications of definitions made to adapt definitions to this glossary.

Literal quotations are indicated by the source code only and no qualifier is attached.

$+/-$ Plus or minus signs, added to the source code, indicate additions or deletions.

* An asterisk indicates a rewording of the definition.

$D$ Draft status, such as national or international drafts or draft proposals, is shown by a capital "D."

\section{GLOSSARY}

ACCESS CONTROL. The tasks imposed on a network or any of its components, performed by hardware, software, and administrative controls, to control usage of the system. Included are monitoring of system operation, insuring of data integrity, user identification, recording system access and changes, and methods for granting users access. [DMC] ${ }^{3}$

ACOUSTIC COUPLER. A type of DATA COMMUNICATION EQUIPMENT that permits use of a telephone handset as a connection to the public telephone network for data transmission, by means of sound transducers.

\section{ASCII. Abbr: American Standard Code for Information Interchange.}

ASYNCHRONOUS TRANSMISSION. Transmission in which time intervals between transmitted characters may be of unequal length. Transmission is controlled by START and STOP ELEMENTS at the beginning and end of each character.

BACKWARD CHANNEL. A channel used for transmission of supervisory or error-control signals. The direction of flow of these signals is in the direction opposite to that in which information is being transferred. The bandwidth of this channel is usually less than that of the FORWARD CHANNEL, i.e., the information channel. [ITU 53.17*]

\footnotetext{
3

Alphabetic source codes in square brackets refer to the list in Section 3.
} 
BACKWARD SUPERVISION. The USE Of SUPERVISORY SEQUENCES fIOM a SECONDARY to a PRIMARY station or node. [ISO*]

BATCH PROCESSING. A technique of data processing in which jobs are collected and grouped before processing. Data thus are normally processed in a deferred mode.

BAUD. (1) $A$ unit of signalling speed equal to the number of discrete conditions or signal events per second. (2) In asynchronous transmission, the unit of signalling speed corresponding to one unit interval per second, $i . e .$, if the duration of the unit interval is $20 \mathrm{milli-}$ seconds, the signalling speed is 50 baud. [ANSI]

BINARY DIGIT. In the binary notation either of the characters 0 or 1 . [ANSI]

BIT. Abbreviation for BINARY DIGIT. [ANSI]

BIT TRANSFER RATE. The number of BITS transferred per unit time, usually expressed in Bits per second (BPS). [ANSI]

BOTH WAY OPERATION. [DIN] SYN: TWO WAY SIMULTANEOUS OPERATION. [ANSI]

BLOCK. A group of digits transmitted as a unit, over which a coding procedure is usually applied for synchronization or error control purposes. Syn: FRAME, TRANSMISSION BLOCK. [ANSI] See also: PACKET.

BYTE. A binary element string operated upon as a unit and usually shorter than a computer word, e.g., six bit, eight bit, or nine bit bytes. See also: BIT. [ANSI]

CENTRALIZED (COMFUTER) NETWORK. A computer network configuration in which a central node provides computing power, control, or other services. Compare: DECENTRALIZED NETWORK.

CHANNEL. (1) That part of a communications system that connects a message source to a message sink. [ANSI] (2) A means of one way transmission. [ANSI] See also: INFORMATION TRANSFER CHANNEL.

CIRCUIT. In communications the complete electrical path providing one or two way communication between two points comprising associated go and return channels. Compare: CHANNEL. [ANSI]

CIRCUIT SWITCHING. A method of communications, where an electrical connection between calling and called stations is established on demand for exclusive use of the CIRCUIT until the connection is released. See also: PACKET SWITCHING, STORE AND FORWARD, MESSAGE SWITCHING. [ITU-e D] 
CODE. (1) A set of unambiguous rules specifying the way in which data may be represented, e.g., the set of correspondences in the standard Code for Information Interchange. (2) In TELECOMMUNICATICNS, a system of rules and conventions according to which the signals representing data can be formed, transmitted, received and processed. (3) In data processing, to represent data or a computer program in a symbolic form that can be accepted by a data processor. [ANSI]

COMMAND LANGUAGE. A user language consisting primarily of procedural operators, each capable of invoking a function to be executed.

COMMON CARRIER. In telecommunication, a public utility company that is recognized by an appropriate regulatory agency as having a vested interest and responsibility in furnishing communication services to the general public, e.g., Western Union, The Bell System. See also: SPECIALIZED COMMON CARRIER, VALUE ADDED SERVICE.

COMMUNICATIONS COMPUTER. A Computer that acts as the interface between another computer or terminal and a network, or a computer controlling data flow in a network. See also: FRONT END COMPUTER, SWITCHING COMPUTER, CONCENTRATOR.

COMMUNICATION CONTROL CHARACTER. In ASCII a functional character intended to control or facilitate transmission over data networks. There are ten CONTROL CHARACTERS specified in ASCII which form the basis for character oriented communications CONTROL PROCEDURES. See also: CONTROL CHARACTER.

(COMPUTER) NETWORK. An interconnection of assemblies of computer systems, terminals and communications facilities. [TNP *]

CONCENTRATOR. A Communications device that provides communications capability between many Iow speed, usually asynchronous CHANNELS and one or more high speed, usually synchronous channels. Usually different speeds, CODES and PROTOCOLS can be accommodated on the low speed side. The low speed channels usually operate in CONTENTION requiring buffering. The concentrator may have the capability to be POLLED by a computer, and may in turn poll terminals. [DCP *]

CONDITIONING. The addition of equipment to leased voice grade LINES to provide specified minimum values of line characteristics required for DATA TRANSMISSION, e.g., equalization and echo suppression. [MAR +]

CONNECT TIME. A measure of system usage by a user, usually the time interval during which the user TERMINAL was ON LINE during a session. See also: CPU TIME.

CONSOLE. (1) A part of a computer used for communication between the operator or maintenance engineer and the computer. [ANSI -] (2) Part of a TERMINAL providing user input and output capability. 
CONTENTION. A condition on a Communications CHANNEL when two or more stations try to transmit at the same time.

CONTROL CHARACTER. (1) A character whose occurrence in a particular context initiates, modifies, or stops a control function. (2) In the ASCII code, any of the 32 characters in the first two columns of the Standard code table. [ANSI +] See also: COMMUNICATIONS CONTROL

CHARACTER.

CONTROL PROCEDURE. The means used to control the orderly communication of information between STATIONS on a DATA LINK. [ANSI] Syn: LINE DISCIPLINE. See also: PROTOCOL.

CONTROL STATION. The STATION on a NETWORK which supervises the network CONTROL PROCEDURES sUCh as POLLING, SELECTING and recovery. It is also responsible for establishing order on the line in the event of CONTENTION, or any other abnormal situation, arising between any stations on the network. [ISO] Compare: TRIBUTARY STATION.

CONVERSATIONAL. Pertaining to a mode of processing that involves stepby-step interaction between the user at a terminal by means of keyboard and display and a computer. See also: INTERACTIVE.

CPU TIME. Central Processing Unit mime, a measure of system usage by a user, based on the total amount of computer processing time used. See also: CONNECT TIME.

DAA. See: DATA ACCESS ARRANGEMENT

DATA ACCESS ARRANGEMENT. DATA COMMUNICATIONS EQUIPMENT furnished by a COMMON CARRIER, permitting attachment of privately owned DATA TERMINAL and DATA COMMUNICATION EQUIPMENT to the common carrier network.

$A b b r: D A A$.

DATA BASE. (1) The entire collection of information available to a computer system. (2) A structured collection of information as an entity or collection of related files treated as an entity.

DATA COMMUNICATION. The interchange of data messages from one point to another over communications channels. See also: DATA TRANSMISSION.

DATA COMMUNICATION EQUIPMENT. The equipment that provides the functions required to establish, maintain, and terminate a connection, the signal conversion, and coding required for communication between DATA TERMINAL EQUIPMENT and data CIRCUIT. The DCE may or may not be an integral part of the DTE or of a computer, e.g., a MODEM. Abbr: DCE. See also: TERMINAL INSTALLATION, DATA LINK.

DATA INTEGRITY. A performance measure based on the rate of undetected errors. 
DATA LINK. An assembIy of TERMINAL INSTALLATIONS and the interconnecting CIRCUITS operating according to a particular method that permits information to be exchanged between terminal installations. NOTE: The method of operation is defined by particular transmission CODES, transmission modes, direction, and control. [ISO +]

DATA SET. (1) A MODEM. (2) A collection of data records, with a logical relation of one to another. [ICS *]

DATA SHARING. The ability of users or computer PROCESSES at several nodes to access data at a single node.

DATA TERMINAL EQUIPMENT. (1) The equipment comprising the data SOURCE, the data SINK, or both. [ANSI] (2) Equipment usually comprising the following functional units: control logic, buffer store, and one or more input or output devices or computers. It may also contain error control, synchronization, and station identification capability. [ISO D] Abbr: DTE. See also: DATA COMMUNICATIONS EQUIPMENT, DATA LINK, TERMINAL INSTALLATION.

DATA TRANSFER CHANNEL. SEe: INFORMATION TRANSFER CHANNEL.

DATA TRANSMISSION. The sending of DATA from one place for reception elsewhere. [ANSI] Compare: DATA COMMUNICATION.

DCE. See: DATA COMMUNICATION EQUIPMENT.

DECENTRALIZED (COMPUTER) NETWORK. A COMputer network, where some of the network control functions are distributed over several network nodes. Compare: CENTRALIZED NETWORK.

DIAL UP LINE. A communications CIRCUIT that is established by a circuit switched connection.

DISTRIBUTED NETWORK. A network configuration in which all node pairs are connected either directly, or through redundant paths through intermediate nodes. Compare: FULLY CONNECTED NETWORK.

DTE. See: DATA TERMINAL EQUIPMENT

DUPLEX OPERATION. [ITU] SEE: TWO WAY SIMULTANEOUS OPERATION. [ANSI]

ECHO CHECK. A method of checking the accuracy of transmission of data in which the received data are returned to the sending end for comparison with the original data. [ANSI]

ECHOPLEX. An ECHO CHECK applied to NETWORK TERMINALS operating in TWO WAY SIMULTANEOUS mode.

EITHER WAY OPERATION [DIN] SEe: TWO WAY ALTERNATE OPERATION [ANSI] FRONT END COMPUTER. A COMMUNICATIONS COMPUTER asSOCiated with a HOST COMPUTER. It may perform line control, message handling, code 
conversion, error control and applications functions such as control and operation of special purpose terminals. [DCP *] See also: COMMUNICATIONS COMPUTER.

FRONT END PROCESSOR. SEe: FRONT END COMPUTER.

FOREIGN EXCHANGE LINE. A Iine offered by a COMMON CARRIER in which a termination in one central office is assigned a number belonging to a remote central office. [ICS *]

FORWARD CHANNEL. A DATA TRANSMISSION CHANNEL in which the direction of transmission coincides with that in which information is being transferred. [ITU 53.16] Compare: BACKWARD CHANNEL.

FORWARD SUPERVISION. USE Of SUPERVISORY SEQUENCES sent from the PRIMARY to a SECONDARY STATION Or NODE. [ISO]

FRAME. See: BLOCK.

FULL DUPLEX OPERATION [US]. SEE: TWO WAY SIMULTANEOUS OPERATION [ANSI], SYN: DUPLEX OPERATION [ITU].

FULLY CONNECTED NETWORK. A NETWORK in which each NODE is directly connected with every other node.

HALF DUPLEX OPERATION [US]. SEE: TWO WAY ALTERNATE OPERATION [ANSI].

HARDWARE. Physical equipment, as opposed to a computer program or method of use, e.g., mechanical, magnetic, electrical or electronic devices. [ISO D]

HEADER. The control information prefixed in a message text, e.g., source or destination code, priority, or message type. Syn: HEADING, LEADER.

HEADING [ANSI]. See HEADER.

HETEROGENEOUS (COMPUTER) NETWORK. A NETWORK Of disSimilar HOST COMPUTERS, such as those of different manufacturers. Compare: HOMOGENEOUS NETWORK.

HIERARCHICAL (COMPUTER) NETWORK. A COMputer NETWORK, in which processing and control functions are performed at several levels by computers specially suited for the functions performed, e.g., in factory or laboratory automation.

HOMOGENEOUS (COMPUTER) NETWORK. A NETWORK Of SIMIIaI HOST COMPUTERS such as those of one model of one manufacturer. Compare: HETEROGENEOUS (COMPUTER) NETWORK. 
HOST COMPUTER. A computer attached to a NETWORK providing primarily services such as computation, data base access or special programs or programming languages. Compare: COMMUNICATIONS COMPUTER.

HOST INTERFACE. The INTERFACE between a COmmunications NETWORK and a HOST COMPUTER.

IDENTIFICATION. (1) The process of providing personal, equipment, or organizational characteristics or codes to gain access to computer programs, processes, files, or data. (2) The process of determining personal, equipment, or organizational characteristics or codes to permit access to computer programs, processes, files or data.

IMP. See: INTERFACE MESSAGE PROCESSOR.

INFORMATION BIT. A bit which is generated by the data source and which is not used for error control by the data transmission system. [ANSI +, MIL]. Compare: OVERHEAD BIT.

INFORMATION PATH. The functional route by which information is transferred in a one-way direction from a single data SOURCE to a single data SINK. [RTM*].

INFORMATION (TRANSFER) CHANNEL. (I) The functional connection between the SOURCE and the SINK data terminal equipments. It includes the circuit and the associated data communications equipments. (2) The assembIy of DATA COMMUNICATION EQUIPMENT and CIRCUITS including a BACKWARD CHANNEL if it exists. [ITU 53.15 -]

INTERACTIVE. Pertaining to exchange of information and control between a user and a computer PROCESS, or between computer processes. See also: CONVERSATIONAL.

INTERCHANGE POINT [DIN]. A location where interface signals are transmitted between equipments by means of electrical interconnections. [DIN] See also: INTERFACE.

INTERFACE. (1) A shared boundary defined by common physical interconnection characteristics, signal characteristics, and meanings of interchanged signals. [ISO D] (2) A device or equipment making possible interoperation between two systems, e.g., a hardware component or a common storage register. [ANSI, ISO D t] See also: INTERCHANGE POINT. (3) A shared logical boundary between two softrare components.

INTERFACE MESSAGE PROCESSOR. In the ARPANET, a communication processor that provides PACKET SWITCHING, LINE DISCIPLINE, and HOST interfacing capability. Abbr: IMP.

LEADER. See: HEADER.

Advanced Research Projects Agency Net, A US Government Sponsored Network. 
LEASED LINE. A non switched CIRCUIT leased from a COMMON CARRIER for exclusive use.

LINE. (I) The portion of a CIRCUIT external to the apparatus consisting of the conductors connecting a telegraph or telephone set to the exchange or connecting two exchanges. (2) The group of conductors on the same overhead route or in the same cable. [ITU 02.09].

\section{LINE DISCIPLINE: See CONTROL PROCEDURE.}

LINK. (1) Any specified relationship between two NODES in a NETWORK. (2) A communications path between two nodes. (3) A DATA LINK. See also: LINE, CIRCUIT, VIRTUAL CIRCUIT.

LINK REDUNDANCY LEVEL. The ratio of actual number of LINKS to the minimum number of LINKS required to connect alI NODES of a NETWORK. See also: FULLY CONNECTED NETWORK.

LOAD SHARING. The distribution of a given load among several computers On a NETWORK.

LOCAL LINE. The portion of a circuit that connects a user's end instrument and a central office. [MIL -].

LOGICAL CIRCUIT. SEe: VIRTUAL CIRCUIT.

LOGIN. A user access procedure to a system involving IDENTIFICATION, ACCESS CONTROL and exchange of NETWORK information between user and system. Syn: LOGON.

LOGOFF. See: LOGOUT.

LOGON. See: LOGIN.

LOGOUT. A user exit procedure from a system often providing usage statistics to the user. Syn: LOGOFF.

MASTER STATION. SYN: PRIMARY STATION.

MESSAGE SWITCHING. A method of handling messages over communications NETWORKS. The entire message is transmitted to an intermediate point (i.e., a switching computer), stored for a period of time, perhaps very short, and then transmitted again towards its destination. The destination of each message is indicated by an address integral to the message. [ITU] Compare: CIRCUIT SWITCHING.

MODEM. Modulator - Demodulator. A device that modulates and demodulates signals transmitted over communications circuits. [ANSI] Syn: DATA SET (I). 
MULTIPLEX. To interleave or simultaneously transmit two or more data streams on a single channel. [ANSI *].

MULTI-POINT CONNECTION. A COnfiguration in which more than two TERMINAL INSTALLATIONS are connected.

NETWORK. (1) An interconnected or interrelated group of NODES. (2) In connection with a disciplinary or problem oriented qualifier, the combination of material, documentation, and human resources that are united by design to achieve certain objectives, e.g., a social science network, a science information network. See also: (COMPUTER) NETWORK.

NETWORK CONTROL PROGRAM. That module of an operating system in a HOST COMPUTER, which establishes and breaks logical connections, communicating with the network on one side, and with user processes within the host computer, on the other side.

NETWORK OPERATIONS CENTER. A specialized NETWORK installation that assists in reliable network operations. Typical activities are monitoring of network status, supervision and coordination of network maintenance, accumulation of accounting and usage data, and user support.

NETWORK REDUNDANCY. The property of a NETWORK to have additional links beyond the minimum number necessary to connect all nodes. See also: LINK REDUNDANCY LEVEL.

NETWORK SECURITY. The totality of measures taken to protect a network from unauthorized access, accidental or willful interference with normal operations, or destruction. This includes protection of physical facilities, software, and personnel security. See also: PRIVACY.

NETWORK TOPOLOGY. The geometric arrangement of LINKS and NODES of a NETTOPK.

NODE. (1) An end point of any branch of a network, or a junction common to two or more branches of a network. [MIL-a]. (2) Any STATION, TERMINAL, TERMINAL INSTALLATION, COMMUNICATIONS COMPUTER, or COMmUnICations computer installation in a COMPUTER NETWORK.

OFFLINE. Pertaining to equipment or devices not under control of the central processing unit. [ANSI]

ONE-WAY ONLY OPERATION [ANSI]. A mode of operation of a DATA LINK in which DATA are transmitted in a preassigned direction over one CHANNEL. SYn: SIMPLEX OPERATION. [US]

ONLINE. (1) Pertaining to equipment or devices under control of the central processing unit. (2) Pertaining to a user's ability to interact with a computer. [ANSI] 
OPERATING SYSTEM. SOFTWARE that controls the execution of computer programs and that may provide scheduling, debugging, input and output control, accounting, storage assignment, data management, and related services. Sometimes called Supervisor, Executive, Monitor, Master Control Program depending on the computer manufacturer.

OVERHEAD BIT. A bit other than an INFORMATION BIT, e.g., check bit, framing bit. [MIL +]

PACKET. A group of BINARY DIGITS including data and control elements which is switched and transmitted as a composite whole. The data and control elements and possibly error control information are arranged in a specified format. [ITU-e *]

PACKET SWITCHING. A DATA TRANSMISSION process, utilizing addressed PACKETS, whereby a CHANNEL is occupied only for the duration of transmission of the packet. NOTE: In certain data communication networks the data may be formatted into a PACKET or divided and then formatted into a number of packets (either by the data terminal equipment or by equipment within the network) for transmission and multiplexing purposes. [ITU-e] See also: CIRCUIT SWITCHING, ṀESSAGE SWITCHING, STORE AND FORWARD.

PASSWORD. A word or string of characters that is recognizable by automatic means and that permits a user access to protected storage, files, or input or output devices.

\section{PHYSICAL CIRCUIT. A CIRCUIT. SE aIso: VIRTUAL CIRCUIT.}

POINT-TO-POINT CONNECTION. (1) A NETWORK COnfiguration in which a connection is established between two, and only two, TERMINAL INSTALLATIONS. The connection may include switching facilities. [DIN] (2) A circuit connecting two points without the use of any intermediate terminal or computer. [ISO D] Compare: MULTI-POINT CONNECTION.

POLLING. The process of inviting another STATION or NODE to transmit DATA. [ISO $D *$ ] Compare: SELECTING.

PRIMARY STATION. (1) The station which at any given instant has the right to select and to transmit information to a SECONDARY STATION, and the responsibility to insure information transfer. There should be only one primary station on a DATA LINK at one time. [ISO *] (2) A STATION which has control of a DATA LINK at a given instant. The assignment of primary status to a given station is temporary and is governed by standardized CONTROL PROCEDURES. Primary status is normally conferred upon a station so that it may transmit a message, but a station need not have a message to be nominated primary station. [ANSI]

PRIVACY. The right of an individual to the control of information about himself. Compare: NETWORK SECURITY. 
PROCESS. (1) A systematic sequence of operations to produce a specified result. [ANSI] (2) A set of related procedures and data undergoing execution and manipulation by one or more computer processing units. [EIO]

PROGRAM SHARING. The ability for several users or computers to utilize a program at another node.

PROTOCOL. A formal set of conventions governing the format and relative timing of message exchange between two communicating PROCESSES. See also: CONTROL PROCEDURE, LINE DISCIPLINE.

REAL TIME SYSTEM. A system performing computation during the actual time the related physical process transpires, so that the results of the computation can be used in guiding the process.

REGIONAL (COMPUTER) NETWORK. (1) A COMPUTER NETWORK whose nOdes provide access to a defined geographical area. (2) A network whose nodes provide access to a specified class of users.

REGULATORY AGENCY. In TELECOMMUIIICATION, an agenCy controliing COMMON and SPECIALIZED CARRIER TARIFFS, e.g., the Federal Communications Commission and the State Public Utility Commissions.

REMOTE BATCH. Pertaining to a process in which jobs are entered into the system in a CONVERSATIONAL mode, and are processed at a later time in the BATCH PROCESSING mode.

REMOTE JOB ENTRY. (1) Submission of jobs through an input device that has access to a computer through a communications link. [ANSI] (2) The mode of operation that allows input of a batch job by a card reader at a remote site and receipt of the output via a line printer or card punch at a remote site. Abbr: RJE.

RESOURCE. Any means available to NETWORK users, such as computational power, brain power, programs, data files, storage capacity, or a combination of these.

RESOURCE SHARING. The joint use of resources available on a network by a number of dispersed users.

RESPONSE TIME. The elapsed time between the generation of the last character of a message at a TERMINAL and the receipt of the first character of the reply. It includes terminal delay, network delay, and service node delay.

RING NETWORK. A COMPUTER NETWORK where each computer is connected to adjacent computers.

RJE. See: REMOTE JOB ENTRY. 
SECONDARY STATION. A STATION that has been selected to receive a transmission from the PRIMARY STATION. The assignment of secondary status is temporary, under control of the primary station, and continues for the duration of a transmission. [ANSI *] Compare: PRIMARY STATION.

SELECTING. A process of inviting another STATION or NODE to receive DATA. [ITU-e *] Compare: POLLING.

SERVICE COMPUTER. SEE: HOST COMPUTER.

SERVICE DELAY. Delay associated with the SERVICE COMPUTER.

SIGNAL ELEMENT. Each of the parts of a digital signal, distinguished from others by its duration, position and sense, or by some of these features onIy. In START-STOP CPERATION a signal element has as a minimum a duration of one UNIT INTERVAL. If several unit intervals of the same sense run together, a signal element of duration of more than one unit element may be formed. Signal elements may be start elements, information elements or stop elements. [EIA *]

SIMPLEX OPERATION [ITU]. SEE: TWO WAY ALTERNATE OPERATION [ANSI].

SIMPLEX OPERATION [US] SEe: ONE WAY ONLY OPERATION. [ANSI] .

SINK. (1) The point of usage of data in a NETWORK. (2) A data TERMINAL INSTALLATION that receives and processes data from a connected CHANNEL.

SOFTWARE. A set of computer programs, procedures, rules and associated documentation concerned with the operation of NETWORK COMPUTERS, e.g., compilers, monitors, editors, utility programs. Compare: HARDWARE.

SOURCE. (1) The point of entry of data in a NETWORK. (2) A data TERMINAL INSTALLATION, that enters DATA into a connected CHANNEL. Data entry may be under operator or machine control as effected by a "message repeat" control signal.

SPECIALIZED COMMON CARRIER. A COmpany that provides private Iine communications services, e.g. voice, teleprinter, data, facsimile transmission. See also: COMMON CARRIER, VALUE ADDED SERVICE.

STAR NETWORK. A computer network with peripheral NODES all connected to one or more computers at a centrally located facility. See also: CENTRALIZED NETWORK.

START ELEMENT. In START-STOP TRANSMISSION, the first element in each character, which serves to prepare the receiving equipment for the reception and registration of the character. [EIA]

START-STOP TRANSMISSION. Asynchronous transmission in which a group of code elements corresponding to a character signal is preceded by a START ELEMENT and is followed by a STOP ELEMENT. [ISO -] 
STATION. That independently-controllable configuration of DATA TERMINAL EQUIPMENT from or to which messages are transmitted on a DATA LINK. It includes those elements which serve as SOURCES or SINKS for the messages, as well as those elements which control the message flow on the link, by means of data communication CONTROL PROCEDURES. [ANSI *] See also: TERMINAL INSTALLATION.

STOP ELEMENT. In START-STOP TRANSMISSION, the last element in each character, to which is assigned a minimum duration, during which the receiving equipment is returned to its rest condition in preparation for the reception of the next character. [EIA]

STORE AND FORWARD. Pertaining to communications where a message is received, stored, and then transmitted.

SUPERVISORY PROGRAMS. Computer programs that have the primary function of scheduling, allocating, and controlling system resources rather than processing data to produce results.

SUPERVISORY SEQUENCE. In data communication, a sequence of COMMUNICATION CONTROL CHARACTERS, and possibly other characters, that perform a defined control function.

SWITCHED CIRCUIT. A circuit that may be temporarily established at the request of one or more of the stations involved.

SYNCHRONOUS TRANSMISSION. A transmission process-such that between any two significant instants there is always an integral number of UNIT INTERVALS. [ISO]

TARIFF. (1) A published rate for services provided by a common or specialized carrier. (2) The means by which regulatory agencies approve such services. The tariff is a part of a contract between customer and carrier. [MAR *]

TELECOMMUNICATION. Any transmission and reception of intelligence of any nature by electromagnetic systems. [ITU $01.01-{ }^{\star}$ ]

TELECONFERENCING. Simultaneous processing of data messages of several participants communicating ONLINE on a NETWORK.

TELEPROCESSING. Automated data processing which makes direct use of DATA TRANSMISSION via switched or long distance non-switched TELECOMMUNCATION facilities. [FIPS PUB 23]

TERMINAL. (1) A point in a communications NETWORK at which data can either enter or leave. [ANSI] (2) A device that permits data entry into or data exit from a computer system or COMPUTER NETWORK, e.g., a data capture device, a teletypewriter, a remote job entry device, or a computer. Terminals may accommodate data in human or machine readable form. 
TERMINAL INSTALLATION. (I) The totality of equipment at a user's installation including DATA TERMINAL EQUIPMENT, DATA COMMUNICATION EQUIPMENT, and necessary support facilities. See also: TERMINAL, STATION. (2) $A$ set composed of a data terminal, a signal converter, and possibly intermediate equipment; this set may be connected to a data processing machine or may be part of it. [ITU 53.05]

TEXT. (1) A sequence of characters forming part of a transmission which is sent from the data SOURCE to the data SINK, and contains the information to be conveyed. It may be preceded by a HEADER and followed by an "end of text"signal. [ISO D-] (2) In ASCII and communications, a sequence of characters, treated as an entity if preceded by a "start of text" and followed by an 'end of text" control character. [ASCII *]

TIME SHARING. The operation of a facility such that many users may use the facility apparently simultaneously.

TRANSMISSION BLOCK. See: BLOCK.

TRANSMISSION CONTROL CHARACTER [ISO]. SEE COMMUNICATION CONTROL CHARACTER [ANSI].

TRANSPARENCY. A property of a communications medium to pass within specified limits a range of signals having one or more defined properties, e.g., a CHANNEL may be CODE transparent, or an equipment may be bit pattern transparent. [ANSI]

TRIBUTARY STATION. A STATION on a DATA LINK that is not a CONTROL STATION. [ANSI *]

TRUNK. A single CIRCUIT between two points, both of which are switching centers or individual distribution points. [MIL] Compare: LOCAL LINE.

TURNAROUND TIME. (1) The elapsed time between submission of a job to a computing center and the return of results. [ANSI] (2) In communications the actual time required to reverse the direction of transmission from send to receive or vice versa when using a TWO WAY ALTERNATE CIRCUIT. Time is required by line propagation effects, modem timing and computer reaction. See also: NETWORK DELAY.

TWO WAY ALTERNATE OPERATION [ANSI]. A mode of operation of a DATA LINK in which DATA may be transmitted in both directions, one way at a time. Syn: EITHER WAY OPERATION [DIN], HALF-DUPLEX OPERATION [US].

TWO WAY SIMULTANEOUS OPERATION [ANSI]. A mode of operation of a DATA LINK in which DATA may be transmitted simultaneously in both directions over two CHANNELS. NOTE: One of the channels is equipped for transmission in one direction while the other is equipped for transmission in the opposite direction. Syn: FULL DUPLEX [US], DUPLEX [ITU].

UNIT ELEMENT. A signal element of one unit element duration.

[EIA] 
UNIT INTERVAL. A unit interval is the duration of the shortest nominal SIGNAL ELEMENT. It is the longest interval of time such that the nominal durations of the signal elements in a synchronous system or the START and INFORMATION ELEMENTS in a start-stop system are whole multiples of this interval. The duration of the unit interval (in seconds) is the reciprocal of the telegraph speed expressed in BAUD. [EIA *]

VALUE ADDED SERVICE. A communications service utilizing communications COMMON CARRIER NETWORKS fOr TRANSMISSION and providing added data services with separate additional equipment. Such added service features may be store and forward message switching, terminal interfacing, and host interfacing.

VIRTUAL CIRCUIT. A connection between a SOURCE and a SINK in a NETWORK that may be realized by different circuit configurations during transmission of a message. Syn: LOGICAL CIRCUIT.

\title{
3. LIST OF SOURCE MATERIAL
}

The following list shows the source material used in this glossary. This list is arranged alphabetically, by source code.

\author{
ANSI (a) American National Standard \\ Vocabulary for Information Processing \\ American National Stanc̈ards Institute X3.12-1970 \\ (b) American National Dictionary for Information Processing \\ American National Standards Institute \\ Draft version, August 1973 \\ (c) American National Standards Institute Committee \\ Publication X3.3/19 February 10, 1965 \\ (not generally available) \\ ASCII USA Standard Code for Information Interchange \\ United States of America Standards Institute \\ USAS X3.4-1967 \\ DCP The Data Communications Planner \\ August 1973 \\ Communications Trends, Inc. \\ Valley Stream, New York 11581 \\ DIN (a) Datenuebertragung, Begriffe \\ (Data Transmission, Concepts) \\ DIN 44302, October 1968 (German National Standard) \\ Deutsche Normen Ausschuss (DNA)
}


(b) Datenuebertragung, Begriffe

(Data Transmission Concepts)

Digital Data Transmission; Vocabulary

(supplement to $D I N$ 44302)

Blatt 11 (Sheet 11)

Entwurf (Draft Proposal), February 1972

Deutsche Normen Ausschuss (DNA)

DMC Data Management Systems Catalog

The MITRE Corporation

$M T P-I 39$

Bedford, Massachusetts

January 1973

Section 6, Glossary

EIA (a) Interface Between Data Terminal Equipment

and Data Communication Equipment Employing Serial

Binary Data Interchange

EIA Standard RS-232-C

Electronic Industries Association

(b) Signal Quality at Interface Between Data

Processing Terminal Equipment and Synchronous

Data Communication Equipment

EIA Standard RS-334

Electronic Industries Association

EIO Organick, Elliot I.

The Multics System

The MIT Press

Cambridge, Massachusetts, 1972

FIPS 23 Federal Information Processing Standards Publication objectives of the Federal Information Processing

Standards Program

FIPS 23, February 15, 1973

ICS IEEE Computer Society

operating systems Glossary

First Draft (not available at this time)

1973

ISO (a) Vocabulary of Data Processing,

International Standards Organization,

(draft sections are in various stages of development and are not generally available at this time) 
(b) Basic Control Procedures for Data Communication Systems

Ist Edition, January 1971

ISO/R 1745-1971 (E)

International Organization for Standardization

ITU (a) List of Definitions of Essential Telecommunications Terms

Part 1, General Terms, Telephone, Telegraphy

International Telecommunications Union

Geneva, 1961

(b) First Supplement to Part 1 of the List of Definitions of Essential Telecommunications Terms

No date

International Telecommunications Union

(c) Second Supplement to Part 1 of the List of Definitions of Essential Telecommunications Terms

International Telecommunications Union

Geneva, 1964

(d) Blue Book

Volume VIII

Data Transmission

International Telecommunications Union

Geneva, November 1964

(e) Special Study Group A - Contribution No. 203

Joint Working Party on NRD - Contribution No. 82

COM Sp. A - No. 203-E

Vocabulary for Data Transmission

Report on Meeting at Geneva, November 25-26, 1971

(also ISO Document ISO/TC 97/SC I

(CCITT-2 282 E)

MAR Telecommunications and the Computer

James Martin

Prentice Hall, Inc.

Englewood Cliffs, New Jersey 1969

MIL Military Standard, Military Communications System Technical Standards

$M I L-S T D-188 \mathrm{C}$

November 24,1969

Department of Defense

Washington, D.C. 20301 
RTM Determination of Performance of Digital Data Communications Systems

$R$. T. Moore

Proceedings International Communications Conference Montreal, Canada, 1971

TNP T. N. Pyke, Jr. and R. P. Blanc

Computer Networking Technology - A State-of-the-Art Review

IEEE Computer Society

Computer, August 1973

Common usage in the US as reported by MAR 
NBS-114A (REV. 7-73)

U.S. DEPT. OF COMM

BIBLIOGRAPHIC DATA

SHEET

1. PUBLICATION OR REPORT NO.

NBS $T N-803$

4. TITLE AND SUBTITI.E

A Guide to Networking Terminology

7. AUTHOR(S)

A. J. Neumann

9. PERFORMING ORGANIZATION NAME AND ADDRESS

\section{NATIONAL BUREAU OF STANDARDS \\ DEPARTMENT OF COMMERCE \\ WASHINGTON, D.C. 20234}

12. Sponsoring Organization Name and Complete Address (Street, City, State, ZIP)

The National Science Foundation

1800 G street, N.W.

Washington, D. C. 20550
5. Publication Date

March 1974

6. Performing Organization Code

8. Performing Organ. Report No.

10. Project/Task/Work Unit No. 640-2415

11. Contract/Grant No. NSF AG-350

13. Type of Report \& Period
Covered Interim

14. Sponsoring Agency Code

15. SUPPI.EMENTARY NOTES

16. ABSTRACT (A 200-word or less factual summary of most significant information. If document includes a significant bibliography or literature survey, mention it here.)

A selected set of terms and definitions relating to computer networking is presented in a coherent manner. An introduction gives the rationale for the glossary, defines the scope by a brief tutorial overview, and states the glossary format and conventions. The glossary is arranged alphabetically and contains about 140 definitions and associated terms. The sources of mary terms are cited and modifiers indicate the status of definitions. A complete listing of source material is appended.

17. KEY WORDS (six to twelve entries; alphabetical order; capitalize only the first letter of the first key word unless a proper name; separated by semicolons) Computer networks; glossary; telecommunications; teleprocessing terminology; vocabulary.

18. AVAILABILITY

$X$ Unlimited

— For Official Distribution. Do Not Release to NTIS

Order From Sup, of Doc., U.S. Government Printing Office Washington, D.C. 20402, SD Cat. No.C13

$\square$ Order From National Technical Information Service (NTIS) Springfield, Virginia 22151
19. SECURITY CLASS (THIS REPURT)

\begin{tabular}{|l|c|} 
UNCL ASSIFIED & 29 \\
\hline $\begin{array}{l}\text { 20. SECURITY CLASS } \\
\text { (THIS PAGE) } \\
\text { UNCLASSIFIED }\end{array}$ & 22. Price \\
\hline
\end{tabular}







\section{NBS TECHNICAL PUBLICATIONS}

PERIODICALS

JOURNAL OF RESEARCH reports National Burcau of Standards research and development in physics, mathematics, and chemistry. Comprehensive scientific papers give complete details of the work, including laboratory data, experimental procedures, and theoretical and mathematical analyses. Illustrated with photographs, drawings, and charts. Includes listings of other NBS papers as issued.

Published in two sections, available separately:

\section{- Physics and Chemistry (Section A)}

Papers of interest primarily to scientists working in these fields. This section covers a broad range of physical and chemical research, with major emphasis on standards of physical measurement, fundamental constants, and properties of matter. Issued six times a year. Annual subscription: Domestic, $\$ 17.00$; Foreign, $\$ 21.25$.

\section{- Mathematical Sciences (Section'B)}

Studies and compilations designed mainly for the inathematician and theoretical physicist. Topics in mathematical statistics, theory of experiment design, numerical analysis, theoretical physics and chemistry, logical design and programming of computers and computer systems. Short numerical tables. Issued quarterly. Annual subscription: Domestic, $\$ 9.00$; Foreign, $\$ 11.25$.

\section{DIMENSIONS, NBS}

The best single source of information concerning the Bureau's measurement, research, developmental, cooperative, and publication activities, this monthly publication is designed for the layman and also for the industry-oriented individual whose daily work involves intimate contact with science and technology -for engineers, chemists, physicists, research managers, product-development managers, and company executives. Annual subscription: Domestic, $\$ 6.50$; Foreign, $\$ 8.25$.

\section{NONPERIODICALS}

Applied Mathematics Series. Mathematical tables, manuals, and studies.

Building Science Series. Research results, test methods, and performance criteria of building materials, components, systems, and structures.

Handbooks. Recommended codes of engineering and industrial practice (including safety codes) developed in cooperation with interested industries, professional organizations, and regulatory bodies.

Special Publications. Proceedings of NBS conferences; bibliographies, annual reports, wall charts, pamphlets, etc.

Monographs. Major contributions to the technical literature on various subjects related to the Bureau's scientific and technical activities.

National Standard Reference Data Series. NSRDS provides quantitative data on the physical and chemical properties of materials, compiled from the world's literature and critically evaluated.

Product Standards. Provide requirements for sizes, types, quality, and methods for testing various industrial products. These standards are developed cooperatively with interested Government and industry groups and provide the basis for common understanding of product characteristics for both buyers and sellers. Their use is voluntary.

Technical Notes. This series consists of communications and reports (covering both other-agency and NBS-sponsored work) of limited or transitory interest.

Federal Information Processing Standards Publications. This series is the official publication within the Federal Government for information on standards adopted and promulgated under the Public Law 89-306, and Bureau of the Budget Circular A-86 entitled, Standardization of Data Elements and Codes in Data Systems.

Consumer Information Series. Practical information, based on NBS research and experience, covering areas of interest to the consuner. Easily understandable language and illustrations provide useful background knowledge for shopping in today's technological marketplace.

\section{BIBLIOGRAPHIC SUBSCRIPTION SERVICES}

The following current-awareness and literature-survey bibliographies are issued periodically by the Bureau :

Cryogenic Data Center Current Awareness Service (Publications and Reports of Interest in Cryogenics). A literature survey issued weekly. Annual subscription : Domestic, $\$ 20.00$; foreign, $\$ 25.00$.

Liquefied Natural Gas. A literature survey issued quarterly. Annual subscription: $\$ 20.00$.

Superconducting Devices and Materials. A literature survey issued quarterly. Annual subscription: $\$ 20.00$. Send subscription orders and remittances for the preceding bibliographic services to the U.S. Department of Commerce, National Technical Information Service, Springfield, Va. 22151.

Electromagnetic Metrology Current Awareness Service (Abstracts of Selected Articles on Measurement Techniques and Standards of Electromagnetic Quantities from D-C to Millimeter-Wave Frequencies). Issued monthly. Annual subscription: $\$ 100.00$ (Special rates for multi-subscriptions). Send subscription order and remittance to the Electromagnetic Metrology Information Center, Electromagnetics Division, National Bureau of Standards, Boulder, Colo. 80302.

Order NBS publications (except Bibliographic Subscription Services) from: Superintendent of Documents, Government Printing Office, Washington, D.C. 20402. 
POSTAGE ANO FEES PAID

OFFICIAL BUSINESS

Penalty for Private Use, $\$ 300$
U.S. DEPARTMENT OF COMMERCE COM-215

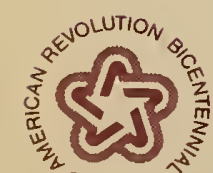

$7>6-1976$ 